\title{
Type E Lymphomatoid Papulosis
}

National Cancer Institute

\section{Source}

National Cancer Institute. Type E Lymphomatoid Papulosis. NCI Thesaurus. Code C139015.

A variant of lymphomatoid papulosis characterized by the presence of atypical lymphocytes which exhibited distinct angioinvasion. 